\title{
6 Year Follow-up of Aortic Valve Reoperation Rates: Carpentier-Edwards Perimount vs St. Jude Medical Trifecta
}

\author{
Herman Stubeda ${ }^{1}$, Hashem Aliter ${ }^{1}$, Ryan Gainer ${ }^{1}$, Chris Theriault ${ }^{2}$, Steve Doucette ${ }^{2}$, and \\ Gregory Hirsch ${ }^{1}$ \\ ${ }^{1}$ Dalhousie University Faculty of Medicine \\ ${ }^{2}$ Nova Scotia Health Authority
}

June 18, 2020

\begin{abstract}
Background The Carpentier-Edwards Perimount valves have a proven track record in aortic valve replacement: good durability, hemodynamic performance, rates of survival, and infrequent valve-related complications and PPM. The St. Jude Medical Trifecta is a newer valve that has shown comparable early and midterm outcomes. Studies show reoperation rates of Trifecta are comparable to Perimount valves, with a few recent studies bringing into focus early SVD, and increased midterm SVD in younger patients. Given that midterm data for Trifecta is still sparse, we wanted to confirm the early low reoperation rates of Trifecta persist over time compared to Perimount. Methods The Maritime Heart Centre Database was searched for isolated AVR or AVR+CABG between January 2011 and December 2016. Primary end point of the study was all-cause reoperation rate. Results 711 Perimount and 453 Trifecta implantations were included. The reoperation hazards were determined for age: 0.96 (0.92-0.99, p=0.02), female (vs male): 0.35 (0.08-1.53, $\mathrm{p}=0.16)$, smoker (vs non-smoker): $2.44(0.85-7.02, \mathrm{p}=0.1)$, and Trifecta (vs Perimount): 2.68 (0.97-7.39, p=0.06). Kaplan-Meier survival analysis in subgroups-age < 60, age [?] 60, male, female, smoker, and non-smoker - showed Perimount having lower reoperation rates than Trifecta in patient younger than $60(\mathrm{p}=0.02)$ and those with smoking history $(\mathrm{p}<0.01)$. Conclusions The rates of reoperation of Perimount and Trifecta were comparable, with Trifecta showing higher rates in patients younger than 60 years, and current smokers. Continued diligence and further independent reporting of midterm reoperation and SVD rates of the Trifecta, including detailed echocardiographic follow up, are needed to confirm these findings.
\end{abstract}

\section{Full Title}

6 Year Follow-up of Aortic Valve Reoperation Rates: Carpentier-Edwards Perimount vs St. Jude Medical Trifecta

\section{Authors and Affiliations}

Herman, Stubeda ${ }^{1}$, Dr. Hashem Aliter, $\mathrm{MD}^{2}$, Ryan A Gainer ${ }^{2}$, Chris Theriault, PEng $^{3}$, Steve Doucette, $\mathrm{MSc}^{3}$, and Dr. Gregory M Hirsch, $\mathrm{MD}^{1,2}$

${ }^{1}$ Faculty of Medicine, Dalhousie University, Halifax, NS, Canada

${ }^{2}$ Division of Cardiac Surgery, Department of Cardiac Surgery, Dalhousie University, Halifax, NS, Canada

${ }^{3}$ Research Methods Unit, Nova Scotia Health Authority, Halifax, NS, Canada

\section{Word Count}

2915

Corresponding Author 
Herman Stubeda, MD Candidate

Research Associate, Cardiovascular Research Group

Room 2006, Halifax Infirmary

QEII Health Sciences Centre 1796 Summer Street Halifax, NS, B3H 3A6

T: +1-902-473-7890

F: +1-902- 473-7149

Email: herman.stubeda@dal.ca

\section{Short Title}

6 Year Follow-up of Aortic Valve Reoperation Rates

\section{Summary}

Carpentier-Edwards Perimount valves have a proven track record of low reoperation rates in aortic valve replacement. The St. Jude Medical Trifecta is a newer valve that has shown comparable outcomes. Given midterm data for Trifecta is still sparse, we wanted to confirm the low early reoperation rates of Trifecta persist over time. The reoperation rates of Perimount and Trifecta were comparable, with Trifecta showing higher rates in patients younger than 60 years, and current smokers.

\section{Abstract}

\section{Background}

The Carpentier-Edwards Perimount valves have a proven track record in aortic valve replacement: good durability, hemodynamic performance, rates of survival, and low rates of valve-related complications and PPM. The St. Jude Medical Trifecta is a newer valve that has shown comparable early and midterm outcomes. Studies show reoperation rates of Trifecta are comparable to Perimount valves, with a few recent studies bringing into focus early SVD, and increased midterm SVD in younger patients. Given that midterm data for Trifecta is still sparse, we wanted to confirm the early low reoperation rates of Trifecta persist over time compared to Perimount.

\section{Methods}

The Maritime Heart Centre Database was searched for isolated AVR or AVR+CABG between January 2011 and December 2016. Primary end point of the study was all-cause reoperation rate.

\section{Results}

711 Perimount and 453 Trifecta implantations were included. The reoperation hazards were determined for age: $0.96(0.92-0.99, \mathrm{p}=0.02)$, female (vs male): $0.35(0.08-1.53, \mathrm{p}=0.16)$, smoker (vs non-smoker): 2.44 (0.85-7.02, $\mathrm{p}=0.1)$, and Trifecta (vs Perimount): $2.68(0.97-7.39, \mathrm{p}=0.06)$. Kaplan-Meier survival analysis in subgroups - age $<60$, age [?] 60, male, female, smoker, and non-smoker - showed Perimount having lower reoperation rates than Trifecta in patient younger than $60(\mathrm{p}=0.02)$ and those with smoking history $(\mathrm{p}<0.01)$.

\section{Conclusions}

The rates of reoperation of Perimount and Trifecta were comparable, with Trifecta showing higher rates in patients younger than 60 years, and current smokers. Continued diligence and further independent reporting of midterm reoperation and SVD rates of the Trifecta, including detailed echocardiographic follow up, are needed to confirm these findings.

\section{Introduction}


Native aortic valves are increasingly replaced with bioprosthetic valves in surgical aortic valve replacement (AVR). ${ }^{1}$ The nature of the bioprosthetic valve design falls susceptible to structural valve deterioration (SVD), but durability has been improving with new designs. ${ }^{2,3}$ The multitude of brands on the market elicits the need to compare prosthesis durabilities and rates of reoperation.

The Carpentier-Edwards Perimount (Edwards Lifesciences, Irvine, CA, USA) and the St. Jude Medical Trifecta valve (St. Jude Medical, St. Paul, MN, USA; recently acquired by Abbott, Illinois, USA) are two popular options. ${ }^{4}$ Perimount has been a frequent choice in our centre because it has a proven track record of good durability, ${ }^{5}$ low incidence of PPM, ${ }^{5,6}$ and rates of survival and valve-related complications comparable to other valves. ${ }^{6}$ The Magna Ease valve is the newest iteration of the Perimount design that received modifications to increase the ease of implantation, including a smaller, contoured sewing ring than previous iterations. ${ }^{6}$ The Manga Ease has demonstrated a hemodynamic performance comparable to its predecessor at early timepoints. ${ }^{7,8}$ The Trifecta is a newer valve, introduced in our center in 2011 . The Trifecta is also implanted in the supra-annular position to generate maximal leaflet opening and hemodynamics similar to a stentless valve. ${ }^{9,10}$ Trifecta has been compared to Magna Ease at early timepoints to show Trifecta having a slight edge in terms of post-operative hemodynamic parameters: lower mean gradient, lower maximum velocity, and larger orifice size at rest and during exercise. ${ }^{9,11-15}$ At early time points, Trifecta also has been reported to have lower rates of severe $\mathrm{PPM},{ }^{13}$ comparable or slightly lower rates of mortality and congestive heart failure, ${ }^{15,16}$ and comparable SVD rates in large series implantation studies. ${ }^{10,17}$

Published data at early time points supports the continued use of both Perimount and Trifecta valves, however, midterm data for Trifecta is still sparse. One recent study of mid-term valve durability has demonstrated that Trifecta is associated with a higher occurrence of reoperation due to SVD compared to the Perimount Magna Ease. ${ }^{4}$ Given the sparseness of midterm outcomes of Trifecta, this study aims to compare Trifecta to the Perimount valve, to confirm that low reoperation rates of Trifecta persist over time.

\section{Methods}

\section{Study Population}

The study population includes all patients who underwent AVR, either isolated or with coronary artery bypass grafting, at the Queen Elizabeth II Health Sciences Centre (QEII HSC, Halifax, NS, Canada) between 2011 and 2016, inclusively. Patient data was obtained from The Maritime Heart Center Cardiac Surgery (MHC) Registry. The MHC is a detailed clinical database that captures preoperative, intraoperative, and postoperative data from all patients undergoing cardiac surgery from 1995 to present in Nova Scotia, Canada. This database was accessed to identify all patients who had their native valve replaced with Perimount or Trifecta valves in AVR, and who of those patients received reoperations for prosthetic valve failure. Perimount, Perimount RSR, Perimount Magna, and Perimount Magna Ease valves were combined into a single Perimount group. Patients were included of any age, sex, and co-morbidity.

\section{Surgical Technique}

Surgical aortic valve replacement was carried out in a typical fashion, with minor variation among surgeons. Briefly, cardiopulmonary bypass with right atrial and aortic cannulation, mild hypothermia, and a combination of retrograde and direct ostial cardioplegia was used. Transverse aortotomy with sharp excision of the valve, followed by valve sizing and implantation using interrupted, pledgeted sutures of 2-0 braided, permanent suture was employed. De-airing after closure of aortotomy was carried out with transesophageal echo (TEE) guidance, and TEE used to evaluate valve function after weaning from bypass.

\section{Endpoints}

The primary endpoint was aortic valve reoperation rates due to any cause, as well as aortic valve reoperationfree survival for reoperations happening between 2011 and 2016, inclusive.

\section{Statistical Analysis}


Statistical analyses were performed using RStudio version 1.2.1335 (RStudio, Inc). Patient characteristics and reoperation rates (event rates) were compared using $\chi^{2}$ or Fischer's Exact Test where appropriate. Timedependent comparison of reoperation-free survival was demonstrated using Kaplan-Meier Survival curves with $95 \% \log -\log$ confidence intervals. The survival curves were log-inverted to demonstrate cumulative hazard of reoperation. The patient population was analysed as a whole and in subgroups based on age, sex, and current smoker status. A Cox-Proportionality Hazard Model comparing age, sex, current smoker status, and valve brand, but no interactions, was developed to determine Hazard Ratios of the variables. Competing risk analysis due to patient mortality was not performed due to lack of patient mortality data.

\section{Results}

711 Perimount and 453 Trifecta valves were implanted in the study period. Patient demographics are summarized in Table 1. Average follow-up times were $2.48 \pm 1.70$ years for Perimount and $2.51 \pm 1.51$ years for Trifecta. No significant differences in patient characteristics and co-morbidities were found between Perimount and Trifecta groups (Table 1).

Reoperation rates were $0.8 \%$ for Perimount and $2.2 \%$ for Trifecta $(\mathrm{p}=0.07)$ for the entire patient cohort over the 6-year study period (Table 2). However, significant differences were found among patients undergoing reoperation in age and smoking history subgroups. Reoperation rates were $1.4 \%$ for Perimount and $7.6 \%$ for Trifecta $(\mathrm{p}=0.04)$ in the age $<60$ years subgroup. Reoperation rates were $0 \%$ for Perimount and $10.2 \%$ for Trifecta $(\mathrm{p}<0.01)$ in the smoking history subgroup. All other subgroups demonstrated non-significant differences in event rates (Table 2).

Reoperation hazards were $1.64 \%$ for Perimount and $3.93 \%$ for Trifecta $(\mathrm{p}=0.06)$ for the entire patient cohort at the 6-year study period end point (Table 3, Fig. 1). However, significant differences were found in the age and smoker subgroups (Fig. 2). Reoperation hazards were $2.44 \%$ for Perimount and $13.1 \%$ ( $\mathrm{p}=$ $0.02)$ in the age $<60$ years subgroup. Reoperation hazards were $0 \%$ for Perimount and $18.0 \%$ for Trifecta $(\mathrm{p}<0.01)$ in the smoker subgroup. All other subgroups demonstrated non-significant differences in event hazards. Interestingly, Trifecta demonstrated noticeable high rate of reoperations at $<6$ months of the study period in subgroups of age $<60$ years, males, and smokers (Fig. 2).

The Cox-proportional Hazards Model showed Hazard Ratios (HR) for age: 0.96 (0.92-0.99, p=0.02), female (vs male): $0.35(0.08-1.53, \mathrm{p}=0.16)$, smoker (vs non-smoker): $2.44(0.85-7.02, \mathrm{p}=0.1)$, and Trifecta (vs Perimount): 2.68 (0.97-7.39, $\mathrm{p}=0.06)$.

\section{Discussion}

In comparison, CE Perimount and SJM Trifecta reoperation hazards were 1.64\% for Perimount and 3.93\% for Trifecta $(\mathrm{p}=0.06)$ at 6 years, which while a 2.75 -fold difference, was not statistically significant $(\mathrm{p}=0.06)$. The hazard function for reoperation with Trifecta implants was significantly higher among patients younger than 60 years of age and among patients with a history of smoking. A recent study of mid-term Trifecta durability has shown Trifecta was associated with high rates of SVD in patients younger than 65 years compared to non-Trifecta group composed of Magna Ease (80.4\%), Intuity (13.1\%), Mitroflow (3.8\%), and Avalus (2.7\%), and the rate difference was also approximately 3-fold. ${ }^{18}$ However, other studies have shown Perimount and Trifecta having similar rates of reoperation or reintervention. For Perimount Magna, reintervention rate was $1 \%$ at 10 years, ${ }^{19}$ and cumulative incidences of explantation for endocarditis and SVD were $1.2 \%$ and $1.0 \%$ at 10 years. ${ }^{20}$ For Trifecta, three studies have reported the freedom from all-cause aortic bioprosthesis reintervention at 5 years to be $98.6 \%,{ }^{21} 96 \%,{ }^{22}$ and $84.5 \% .{ }^{23}$ There is variability between studies and surgical centers, which demonstrates Perimount and Trifecta can have comparable rates of reoperation, but with a slight preponderance in current literature for higher rates of SVD in Trifecta.

In this study, Trifecta demonstrated a noticeably high rate of reoperations at $<6$ months of the study period in higher risk subgroups: age $<60$ years, males, and smokers (Fig. 2). Trifecta failures at $<46$ months have also been described before and attributed in part to insufficient surgeon experience with a new valve leading to PPM and higher postoperative peak and mean AV gradients, ${ }^{20}$ and to mechanical issues: tear of the 
noncoronary cusp, circumferential pannus formation composed of fibrofatty tissue in the inflow portion, and leaflet calcification concentrated around the posts in the outflow portion leading to restricted leaflet mobility, stenosis, and regurgitation. ${ }^{24,25}$ Only 1 out of 16 patients had active endocarditis during reoperation, due to which the prosthesis may have failed. Otherwise, the cause of reoperation was not available, which is a limitation of this study.

\section{Study Limitations}

The study end point was reoperation, which limited the conclusions drawn about bioprosthesis failure rates. First, the valve failure rates may be lower than actual with this approach, as patients may be lost to valve-related mortality, ${ }^{26}$ inoperable status, ${ }^{19}$ out-of-province reoperations, and non-operative management of failing aortic valves rather than referral for reoperation. Indeed, studies that focus only on reoperation rates systematically underestimate the real incidence of SVD. ${ }^{27}$ Thus our approach underestimates valve failure rates, resulting in lost statistical power in comparing SVD by valve type. Overall event rates were low, limiting statistical power as well as the potential generalizability of the results.

This has also caused the Cox proportional hazards model to fail to show significance of smoking on prosthesis reoperation, which is otherwise a known predictor of $\mathrm{SVD}^{27}$. This precluded us from examining other known predictors of SVD, or to make a meaningful distinction between SVD and non-SVD mechanisms.

Echocardiogram data can reveal specific cause of valve failure, such as SVD, non-structural VD, or infective endocarditis. ${ }^{28}$ Such data would demonstrate more accurate rates of prosthesis failure requiring reoperation.

\section{Conclusion}

This study compared reoperation rates of CE Perimount and SJM Trifecta aortic bioprostheses for AVR. The rates of reoperation were comparable, with Trifecta showing higher rates in patients younger than 60 years, and current smokers. Literature has also shown that reoperation rates of Trifecta are comparable to Perimount valves, with a few recent studies bringing into focus early SVD in Trifecta, and increased midterm SVD in younger patients. Continued diligence and further independent reporting of midterm reoperation and SVD rates of the Trifecta, including detailed echocardiographic follow up, are needed to confirm these findings.

\section{Acknowledgements}

None

\section{Funding Sources}

Division of Cardiac Surgery Research Fund

\section{Disclosures}

None

\section{References}

1. Brown JM, O'Brien SM, Wu C, Sikora JAH, Griffith BP, Gammie JS. Isolated aortic valve replacement in North America comprising 108,687 patients in 10 years: changes in risks, valve types, and outcomes in the Society of Thoracic Surgeons National Database. J Thorac Cardiovasc Surg . 2009;137(1):82-90.

2. Schoen FJ, Levy RJ. Founder's Award, 25th Annual Meeting of the Society for Biomaterials, perspectives. Providence, RI, April 28-May 2, 1999. Tissue heart valves: current challenges and future research perspectives. J Biomed Mater Res . 1999;47(4):439-465.

3. Head SJ, Çelik M, Kappetein AP. Mechanical versus bioprosthetic aortic valve replacement. Eur Heart $J$ . 2017;38(28):2183-2191.

4. Biancari F, Valtola A, Juvonen T, et al. Trifecta versus Perimount Magna Ease Aortic Valve Prostheses. Ann Thorac Surg . Published online February 12, 2020. 
5. Kume Y, Fujita T, Fukushima S, et al. Reducing Prosthesis-Patient Mismatch With Edwards Magna Prosthesis for Aortic Valve Replacement.Circ J Off J Jpn Circ Soc . 2017;81(4):468-475.

6. Fiegl K, Deutsch M-A, Rondak I-C, Lange R, Guenzinger R. Matched Comparison of Two Different Biological Prostheses for Complete Supra-annular Aortic Valve Replacement. Thorac Cardiovasc Surg . 2015;63(6):459-466.

7. Nishioka N, Yamada A, Ujihira K, et al. Outcomes of surgical aortic valve replacement using CarpentierEdwards PERIMOUNT bioprosthesis series in elderly patients with severe aortic valve stenosis: a retrospective cohort study. Gen Thorac Cardiovasc Surg . 2016;64(12):728-734.

8. Wendt D, Thielmann M, Plicht B, et al. The new St Jude Trifecta versus Carpentier-Edwards Perimount Magna and Magna Ease aortic bioprosthesis: is there a hemodynamic superiority? J Thorac Cardiovasc Surg . 2014;147(5):1553-1560.

9. Bach DS, Patel HJ, Kolias TJ, Deeb GM. Randomized comparison of exercise haemodynamics of Freestyle, Magna Ease and Trifecta bioprostheses after aortic valve replacement for severe aortic stenosis. Eur J CardioThorac Surg Off J Eur Assoc Cardio-Thorac Surg . 2016;50(2):361-367.

10. Bavaria JE, Desai ND, Cheung A, et al. The St Jude Medical Trifecta aortic pericardial valve: results from a global, multicenter, prospective clinical study. J Thorac Cardiovasc Surg . 2014;147(2):590-597.

11. Colli A, Marchetto G, Salizzoni S, et al. The TRIBECA study: (TRI)fecta (B)ioprosthesis (E)valuation versus (C)arpentier Magna-Ease in (A)ortic position. Eur J Cardio-Thorac Surg Off J Eur Assoc CardioThorac Surg . 2016;49(2):478-485.

12. Stock S, Lohmann I, Hanke T, et al. Rest and exercise haemodynamics in patients with one of two stented bioprostheses and in healthy controls with small aortic annuli. Interact Cardiovasc Thorac Surg . 2018;26(3):425-430.

13. Domoto S, Niinami H, Uwabe K, et al. Comparison of early haemodynamics of 19-mm aortic valve bioprostheses in patients with a small aortic annulus. Interact Cardiovasc Thorac Surg . 2016;22(1):19-25.

14. Ugur M, Suri RM, Daly RC, et al. Comparison of early hemodynamic performance of 3 aortic valve bioprostheses. J Thorac Cardiovasc Surg . 2014;148(5):1940-1946.

15. Yanagawa B, Tam DY, Hong K, et al. Magna Ease Versus Trifecta Early Hemodynamics: A Systematic Review and Meta-analysis. Innov Phila Pa . 2018;13(4):267-272.

16. Rubens FD, Gee Y-Y, Ngu JMC, Chen L, Burwash IG. Effect of aortic pericardial valve choice on outcomes and left ventricular mass regression in patients with left ventricular hypertrophy. J Thorac Cardiovasc Surg . 2016;152(5):1291-1298.e2.

17. Goldman S, Cheung A, Bavaria JE, Petracek MR, Groh MA, Schaff HV. Midterm, multicenter clinical and hemodynamic results for the Trifecta aortic pericardial valve. J Thorac Cardiovasc Surg . 2017;153(3):561$569 . \mathrm{e} 2$.

18. Fukuhara S, Shiomi S, Yang B, et al. Early Structural Valve Degeneration of Trifecta Bioprosthesis. Ann Thorac Surg . 2020;109(3):720-727.

19. Theologou T, Harky A, Shaw M, et al. Mitroflow and Perimount Magna 10 years outcomes a direct propensity match analysis to assess reintervention rates and long follow-up mortality. J Card Surg . 2019;34(11):1279-1287.

20. Johnston DR, Soltesz EG, Vakil N, et al. Long-term durability of bioprosthetic aortic valves: implications from 12,569 implants. Ann Thorac Surg . 2015;99(4):1239-1247.

21. Glaser N, Franco-Cereceda A, Sartipy U. Late survival after aortic valve replacement with the perimount versus the mosaic bioprosthesis. Ann Thorac Surg . 2014;97(4):1314-1320. 
22. Kilic A, Sultan I, Navid F, et al. Trifecta Aortic Bioprosthesis: Midterm Results in 1,953 Patients From a Single Center. Ann Thorac Surg . 2019;107(5):1356-1362.

23. Lehmann S, Meyer A, Schroeter T, et al. Midterm Durability and Hemodynamic Performance of a Third-Generation Bovine Pericardial Prosthetic Aortic Valve: The Leipzig Experience. Ann Thorac Surg . 2017;103(6):1933-1939.

24. Kalra A, Rehman H, Ramchandani M, et al. Early Trifecta valve failure: Report of a cluster of cases from a tertiary care referral center. J Thorac Cardiovasc Surg . 2017;154(4):1235-1240.

25. Kaneyuki D, Nakajima H, Asakura T, et al. Early First-Generation Trifecta Valve Failure: A Case Series and a Review of the Literature.Ann Thorac Surg . 2020;109(1):86-92.

26. Hernandez-Vaquero D, Diaz R, Pascual I, et al. The Prevalence of Patient-Prosthesis Mismatch Can Be Reduced Using the Trifecta Aortic Prosthesis. Ann Thorac Surg . 2018;105(1):144-151.

27. Rodriguez-Gabella T, Voisine P, Puri R, Pibarot P, Rodés-Cabau J. Aortic Bioprosthetic Valve Durability: Incidence, Mechanisms, Predictors, and Management of Surgical and Transcatheter Valve Degeneration. $J$ Am Coll Cardiol . 2017;70(8):1013-1028.

28. Anselmi A, Ruggieri VG, Lelong B, et al. Mid-term durability of the Trifecta bioprosthesis for aortic valve replacement. J Thorac Cardiovasc Surg . 2017;153(1):21-28.e1.

\section{Hosted file}

Table 1.docx available at https://authorea.com/users/334709/articles/460650-6-year-followup-of-aortic-valve-reoperation-rates-carpentier-edwards-perimount-vs-st-jude-medicaltrifecta

\section{Hosted file}

Table 2.docx available at https://authorea.com/users/334709/articles/460650-6-year-followup-of-aortic-valve-reoperation-rates-carpentier-edwards-perimount-vs-st-jude-medicaltrifecta

\section{Hosted file}

Table 3.docx available at https://authorea.com/users/334709/articles/460650-6-year-followup-of-aortic-valve-reoperation-rates-carpentier-edwards-perimount-vs-st-jude-medicaltrifecta

\section{Hosted file}

Figure 1.docx available at https://authorea.com/users/334709/articles/460650-6-year-followup-of-aortic-valve-reoperation-rates-carpentier-edwards-perimount-vs-st-jude-medicaltrifecta

\section{Hosted file}

Figure 2.docx available at https://authorea.com/users/334709/articles/460650-6-year-followup-of-aortic-valve-reoperation-rates-carpentier-edwards-perimount-vs-st-jude-medicaltrifecta 